Scientific Review - Engineering and Environmental Sciences (2020), 29 (3), 343-354

Sci. Rev. Eng. Env. Sci. (2020), 29 (3)

Przegląd Naukowy - Inżynieria i Kształtowanie Środowiska (2020), 29 (3), 343-354

Prz. Nauk. Inż. Kszt. Środ. (2020), 29 (3)

http://iks.pn.sggw.pl

DOI 10.22630/PNIKS.2020.29.3.29

Mustafa O. ORIBI ${ }^{1,2}$, Asraa K. ABDULKAREEM ${ }^{3}$

${ }^{1}$ Iraqi Ministry of Agriculture, Agricultural Meteorological Network

${ }^{2} \mathrm{MSc}$ student at the Mustansiriyah University, College of Science

${ }^{3}$ Mustansiriyah University, College of Science

\title{
Scenarios to reduce evaporation from class A evaporation pan by using windbreaks
}

Key words: evaporation basin, windbreaks natural, open water bodies, wind speed

\section{Introduction}

Evaporation refers to the loss of water from the surface of a water body to the atmosphere, that is, the conversion of water from the liquid to the gaseous state (Yao, Zhang, Lemckert, Brook \& Schouten, 2010).

Evaporation is way for wasting water around the world. There are various ways to control evaporation from reservoirs such as physical, biological, mechanical, and chemical methods (Hashemi Monfared, Rezapour \& Zhian, 2019a).

Evaporation increases with increased air temperatures, high wind speeds and low humidity. Since a large amount of water is wasted every year due to evaporation from storage tanks, evaporation of water from large water bodies affects the hydrological cycle.
Among the hydrological cycle, evaporation is the most difficult to estimate due to the complex interactions between the components of the Earth system and atmosphere (Singh \& Xu, 1997).

There are many ways to reduce evaporation from lakes and water tanks, and these processes are not new as they started since 1960 when volatile oils were used as a layer covering the surface of the water to protect it from evaporation (Benzaghta \& Mohamad, 2009).

The following methods are used to reduce evaporation such as floating lids where act as a lid on the surface of the water to reduce evaporation, such as polymers, foam wax and polystyrene (Cooley \& Myers, 1973). Floating objects same principle as floating covers, however rather than a continuous cover multiple individual units are used, often floating freely. This allows for easier installation and maintenance of the cover but reduces the evaporation reduction efficiency (Cooley, 1970). Shadow struc- 
tures are used to reduce wind speed and the amount of solar radiation falling on the surface of the water. This technique is suitable for small water tanks (Álvarez, Baille, Martínez \& Real, 2006), chemical caps. This method are based on the use of long chain alcohol to form a thin layer on the surface of the water to reduce evaporation. These layers are biodegradable and need to be reapplied every 1 to 4 days. Chemical methods are not effective as the physical methods (Erick, 2007).

Windbreaks using to analyse the factors that cause evaporation, and thus will reduce evaporation from the lakes. This method is the best of all the mentioned methods. The reason in addition to reducing evaporation, the windbreaks also using to protect plants from the influence of winds that cause diseases and pests. It also plays an important role in reducing pollutants (Campi, Palumbo \& Mastrorilli, 2009; Hong, Lee \& Seo, 2015).

A windbreak is a barrier composed of trees and shrubs that redirects and modifies the force of the wind. Part of the air current is diverted over the topes of the trees and part of it filters through the trees (Manual, 1990).

Windbreaks are barriers used to reduce and redirect wind. They usually consist of trees and shrubs, but may also be perennial or annual crops and grasses, fences, or other materials. The reduction in wind speed behind windbreaks modifies the environmental conditions or microclimate in the sheltered zone. As wind blows against a windbreaks, air pressure builds up on the windward side (the side towards the wind), and large quantities of air move up and over the top or around the ends of the wind- breaks. windbreaks structure - height, density, number of rows, species, composition, length, orientation, and continuity - determines the effectiveness of a windbreaks in reducing wind speed and altering the microclimate (Brandle, Hintz \& Sturrock, 2012).

Because of the importance of this method, many researchers study research or use theoretical models to calculate the effect of windbreaks on reducing wind speed and evaporation.

Yusaiyin and Tanaka (2009) used wind tunnels and windbreaks to study coefficient of drag for different fenders by Navier-Stokes (RANS) equation, which depends on the width of the fenders, the result showed the width of windbreaks reduce wind velocity from 15 to $20 \%$ (Yusaiyin \& Tanaka, 2009).

Kim with collaborators used the Fluid Motion Program (CFD) in the design of a windbreak fence simulation to reduce fugitive dust in open areas. This was done by studying the different wind speeds based on climatic data as well as the characteristics of the windbreaks, such as the height and density of the fenders and the distance between the fenders. the importance of this research is to provide a good way to predict and reduce flying dust in open areas (Kim et al., 2018).

Vacek with collaborators studied three types of windbreaks and their effect on high wind speeds. This was done by measuring wind speed for different distances before the fenders, and after the fenders, a station was set as a source of control. The results of the experiment showed that the height and porosity of the fenders play an important and influential role in reducing the wind speed (Vacek et al., 2018). 
Hashemi Monfared, Zoraghi, Azhdary Moghaddam, Dehghani Darmian and Abdollahi (2019) in their pilot study focused on the accurate measurement of evaporation and a new approach to reduce this phenomenon in southeastern Iran (Zahedan). After evaluating the experimental results, six relationships were extracted to accurately estimate evaporation in arid regions. The glass lids were used to reduce evaporation. The cover is made of wasted glass, rubber and some floating glue. The results showed a $40 \%$ decrease in the evaporation rate.

Hashemi Monfared with collaborators aimed to study the effect of windbreaks on reducing evaporation of lakes and reservoirs in dry areas, identifying the optimum site and planning windbreaks using the FLUENT model. The results showed that winds are the most important factor affecting evaporation in the Shanima region in Sistan, Iran, and that solid windbreaks have a role in effectively reducing evaporation rates (Hashemi Monfared et al., 2019b).

The importance of this research is an applied research which serves society in terms of its applicability to reduce evaporation in environmentally friendly ways, which are natural windbreaks (trees).

\section{Material and methods}

In this section we will look at the study area, climate data and tools used in the experiment.

\section{Meteorological data}

The data used in this study were obtained for the monthly wind speed and direction, from the Meteorological and
Seismological Organization (IMOS), other elements, air temperature, solar irradiance, and dew point depending on the climatic stations for the Meteorological Network Iraqi Agricultural.

\section{Study area}

The study area is an experiment that has developed similar conditions to the station conditions, so that the results are more accurate and realistic.

\section{Experiment}

The tools used in the experiment are the class A evaporation pan is a standard device for manual measurement of evaporation (Australian Bureau of Meteorology class A type), diameter $122 \mathrm{~cm}$ and height $25 \mathrm{~cm}$, windbreaks from natural trees Conocarpus type, number of trees 9 , distribution trees in three rows, each row contains three trees, variable height trees $50-100 \mathrm{~cm}$, method of installing windbreaks (parallel and crosses), electric air fan, to direct the air on the evaporation tank and measure the wind speed before and after using the windbreaks, anemometer digital sensor (Banggood, China) to measuring wind speed $\left[\mathrm{m} \cdot \mathrm{s}^{-1}\right.$, $\left.\mathrm{km} \cdot \mathrm{h}^{-1}, \mathrm{ft} \cdot \mathrm{min}^{-1}, \mathrm{knots}, \mathrm{mi} \cdot \mathrm{h}^{-1}\right]$ and the finally glass house.

In this paper the researcher depending on modified Penman equation for Iraq conditions to calculate evaporation from open water surfaces such as lakes and rivers (Al-Echrish, 2001).

$$
\begin{aligned}
& \left(e_{s}-e_{a}\right)=33.8639[(0.00738 T+ \\
& +0.8072)^{8}-\left(0.00738 T_{d}+0.8072\right)^{8}- \\
& \left.-0.0000342\left(T-T_{d}\right)\right]
\end{aligned}
$$


$E=\frac{47.7855726 e^{(1.8 t-180 \cdot 0.1024-0.01066) \ln (R / 4.1855)}-0.0047785+0.64\left(e_{s}-e_{a}\right)(0.028+0.00009 U)}{0.88153664(0.00738 T+0.8072)^{7}+0.91132775}$

where:

$E$ - daily evaporation rate [cm],

$R$ - solar radiation $\left[\mathrm{J} \cdot \mathrm{cm}^{-2}\right]$,

$e_{s}-e_{a}-$ difference of saturated vapour pressure and air vapour pressure $[\mathrm{kPa}]$,

$U$ - wind speed at $10 \mathrm{~m}$ height above the ground $\left[\mathrm{km} \cdot \mathrm{day}^{-1}\right]$.

$T$ - air temperature at $1.5 \mathrm{~m}$ above the ground this height is stander in station $\left[{ }^{\circ} \mathrm{C}\right]$,

$T_{d}$ - dew point $\left[{ }^{\circ} \mathrm{C}\right]$.

This experiment carried out by using glass house $(1.5 \times 2 \mathrm{~m})$ with an evaporation basin, to provide organized climatic conditions, then the windbreaks were placed in a direct direction with the wind direction and the measurement of the wind speed and the rate of evaporation twice using a wind gauge and the Benman equation respectively without windbreaks and with bumpers the wind. After that, three basic scenarios were adopted for the weather elements that affect the evaporation process during the summer according to the modified Benman equation for the climatic conditions in Iraq. The main factors are temperature, solar radiation, wind speed, dew point.

- The first scenario (S1) assumes that all climatic factors (air temperature, wind speed, dew point, solar radiation) are maximum.

- The second scenario (S2) assumes that all climatic factors are minimum.

- The third scenario (S3) assumes that all climatic factors are average.

Each of these three scenarios consist of sub-scenario according to the method of windbreaks installation and the num-

ber of its rows and height. Windbreaks have installed in parallel way and presented $(\alpha)$, and in cross-section $(\beta)$, and first row was presented (R1), second row (R2) and third row (R3). Every row has three trees, and the distance between trees and rows is $15 \times 15 \mathrm{~cm}$, the trees height is vary from $50(A)$ to $100 \mathrm{~cm}(B)$.

\section{Results and discussion}

\section{Effect windbreak on wind speed}

Characteristics of wind velocity reduction behind the windbreak can be expressed by many parameters. The most commonly used are shelter length and width windbreaks. Windbreaks can protect a downwind area whose horizontal length is equal to up to 10 times the trees' height over which wind velocity in the downstream is reduced 20\% (Manual, 1990; Yusaiyin \& Tanaka, 2009).

Windbreaks reduce average wind speed in three ways. First, the absorb some of the wind energy by means of frictional drag as the moving air passes through and around them. Second, they deflect wind to higher levels. And third, windbreak redirect relatively smooth, horizontal airflow into random directions. That is more turbulence is created (Manual, 1990).

Through the results of the experiment it was found that the increase in the height of the windbreaks (trees) decreases the wind speed in all scenarios for the study period, as showing in Tables 1,2 and 3 . 
TABLE 1. Extent of the effect windbreaks on reduce wind speed by experi scenarios in June

\begin{tabular}{|c|c|c|c|c|c|c|c|c|c|c|c|c|c|}
\hline \multirow{4}{*}{$\mathrm{S}$} & \multirow{4}{*}{$\begin{array}{c}\text { Actual } \\
\text { wind } \\
\text { speed } \\
{\left[\mathrm{m} \cdot \mathrm{s}^{-1}\right]}\end{array}$} & \multicolumn{12}{|c|}{ With using windbreak $\left[\mathrm{m} \cdot \mathrm{s}^{-1}\right]$} \\
\hline & & \multicolumn{6}{|c|}{$\alpha$} & \multicolumn{6}{|c|}{$\beta$} \\
\hline & & \multicolumn{3}{|c|}{$A$} & \multicolumn{3}{|c|}{$B$} & \multicolumn{3}{|c|}{$A$} & \multicolumn{3}{|c|}{$B$} \\
\hline & & $\mathrm{R} 1$ & $\mathrm{R} 2$ & R3 & $\mathrm{R} 1$ & $\mathrm{R} 2$ & R3 & $\mathrm{R} 1$ & $\mathrm{R} 2$ & R3 & $\mathrm{R} 1$ & $\mathrm{R} 2$ & R3 \\
\hline S1 & 8 & 7.7 & 7.3 & 6.5 & 7.1 & 6.5 & 5.6 & 7.7 & 7.1 & 6.2 & 7.1 & 6.1 & 5.2 \\
\hline S2 & 2 & 1.7 & 1.3 & 0.5 & 1.1 & 0.5 & 0 & 1.7 & 0.9 & 0 & 1.1 & 0.3 & 0 \\
\hline S3 & 5 & 4.7 & 4.4 & 3.6 & 4.1 & 3.5 & 2.6 & 4.7 & 4 & 3.1 & 4.1 & 3.2 & 2.1 \\
\hline
\end{tabular}

Actual - measuring wind speed without using windbreaks; $\alpha$ - distributing windbreak in parallel case, $\beta$-distributing windbreak in intersection case; $A$ - windbreaks' height of $50 \mathrm{~cm}, B$ - windbreaks' height of $100 \mathrm{~cm}$; R1 - one row of trees, R2 - two rows of trees, R3 - three rows of trees.

TABLE 2. Extent of the effect windbreaks on reduce wind speed by experi scenarios in July

\begin{tabular}{|c|c|c|c|c|c|c|c|c|c|c|c|c|c|}
\hline \multirow{4}{*}{$\mathrm{S}$} & \multirow{4}{*}{$\begin{array}{c}\text { Actual } \\
\text { wind } \\
\text { speed } \\
{\left[\mathrm{m} \cdot \mathrm{s}^{-1}\right]}\end{array}$} & \multicolumn{12}{|c|}{ With using windbreak $\left[\mathrm{m} \cdot \mathrm{s}^{-1}\right]$} \\
\hline & & \multicolumn{6}{|c|}{$\alpha$} & \multicolumn{6}{|c|}{$\beta$} \\
\hline & & \multicolumn{3}{|c|}{$A$} & \multicolumn{3}{|c|}{$B$} & \multicolumn{3}{|c|}{$A$} & \multicolumn{3}{|c|}{$B$} \\
\hline & & $\mathrm{R} 1$ & $\mathrm{R} 2$ & R3 & $\mathrm{R} 1$ & $\mathrm{R} 2$ & R3 & R1 & $\mathrm{R} 2$ & $\mathrm{R} 3$ & $\mathrm{R} 1$ & $\mathrm{R} 2$ & R3 \\
\hline $\mathrm{S} 1$ & 9 & 8.7 & 8.3 & 7.5 & 8.1 & 7.5 & 6.6 & 8.7 & 8.1 & 7.2 & 8.1 & 7.3 & 6.2 \\
\hline $\mathrm{S} 2$ & 1.7 & 1.5 & 1.1 & 0.3 & 1 & 0.5 & 0 & 1.5 & 0.6 & 0 & 1 & 0.1 & 0 \\
\hline S3 & 5.3 & 5 & 4.6 & 3.8 & 4.4 & 3.8 & 3 & 5 & 4.2 & 3.2 & 4.4 & 3.5 & 2.3 \\
\hline
\end{tabular}

Actual - measuring wind speed without using windbreaks; $\alpha$ - distributing windbreak in parallel case, $\beta$-distributing windbreak in intersection case; $A$ - windbreaks' height of $50 \mathrm{~cm}, B$ - windbreaks' height of $100 \mathrm{~cm}$; R1 - one row of trees, R2 - two rows of trees, R3 - three rows of trees.

TABLE 3. Extent of the effect windbreaks on reduce wind speed by experi scenarios in August

\begin{tabular}{|c|c|c|c|c|c|c|c|c|c|c|c|c|c|}
\hline \multirow{4}{*}{$\mathrm{S}$} & \multirow{4}{*}{$\begin{array}{c}\text { Actual } \\
\text { wind } \\
\text { speed } \\
{\left[\mathrm{m} \cdot \mathrm{s}^{-1}\right]}\end{array}$} & \multicolumn{12}{|c|}{ With using windbreak $\left[\mathrm{m} \cdot \mathrm{s}^{-1}\right]$} \\
\hline & & \multicolumn{6}{|c|}{$\alpha$} & \multicolumn{6}{|c|}{$\beta$} \\
\hline & & \multicolumn{3}{|c|}{$A$} & \multicolumn{3}{|c|}{$B$} & \multicolumn{3}{|c|}{$A$} & \multicolumn{3}{|c|}{$B$} \\
\hline & & $\mathrm{R} 1$ & $\mathrm{R} 2$ & R3 & $\mathrm{R} 1$ & $\mathrm{R} 2$ & $\mathrm{R} 3$ & $\mathrm{R} 1$ & $\mathrm{R} 2$ & $\mathrm{R} 1$ & $\mathrm{R} 1$ & $\mathrm{R} 2$ & $\mathrm{R} 1$ \\
\hline $\mathrm{S} 1$ & 12 & 11.7 & 11.3 & 10.3 & 11.1 & 10.3 & 9.6 & 11.7 & 11 & 9.9 & 11.1 & 10.1 & 9.2 \\
\hline $\mathrm{S} 2$ & 2.5 & 2.2 & 1.8 & 1 & 1.6 & 1 & 0.1 & 2.2 & 1.5 & 0.6 & 1.6 & 0.7 & 0 \\
\hline S3 & 7.2 & 7 & 6.5 & 5.7 & 6.3 & 5.7 & 4.9 & 7 & 6.3 & 5.2 & 6.3 & 5.5 & 4.3 \\
\hline
\end{tabular}

Actual - measuring wind speed without using windbreaks; $\alpha$ - distributing windbreak in parallel case, $\beta$-distributing windbreak in intersection case; $A$ - windbreaks' height of $50 \mathrm{~cm}, B$ - windbreaks' height of $100 \mathrm{~cm}$; R1 - one row of trees, R2 - two rows of trees, R3 - three rows of trees. 
For example, the wind speed for June in $\mathrm{S} 1$ is $9 \mathrm{~m} \cdot \mathrm{s}^{-1}$, decreased to $8.7 \mathrm{~m} \cdot \mathrm{s}^{-1}$ in the case A while decreased to $8.1 \mathrm{~m} \cdot \mathrm{s}^{-1}$ in case B. Also, increasing the number of rows reduces the wind speed, as the wind decreases in the R3 more than the R1 and $\mathrm{R} 2$. The reason is due to the increased roughness surface.

As for the method of distributing trees in the rows, it appears that the intersection case reduces the winds more than the parallel case in the R2 and R3, but in the R1 no difference occurred because the porosity reduces when the windbreaks installed in crosses case as the porosity is responsible for the air volume increment that passes the windbreaks and this lead to pressure difference between the winds face that responsible for increasing the effective area that encounters the wind direction.

In addition, the number of windbreaks is playing an important role as the air density increases when the number of windbreaks is increased and this lead to affect and obstruct the airflow. The best experiment results in second scenario for the three months (summer season) because the wind velocity in minimum case, were when the height of the fenders was $100 \mathrm{~cm}$, the fenders number of 3 , and the method of installing the fenders in cross case [S2 $\beta B R 3$ ] recorded the highest rate of wind velocity reduction to $(100 \%)$ of its original value.

\section{Effect wind speed on evaporation}

According to Equation (1), a direct correlation with temperature, wind speed and relative humidity relationship has been found. This means that the increase in temperature and wind speed increases evaporation rates. As a result, changing one unit of wind speed leads to a clear change in evaporation compared to other factor such as humidity.

Height, density, and orientation are the major factors determining protection provided by windbreaks, but other factors such as width, cross-sectional shape, and composition are also important (Brandle \& Finch, 1991).

Low density of windbreaks is responsible for increasing the volume of air passing. This leads to a pressure difference between two sides of the wind, responsible for the increase in an effective area on the side of the wind and the porosity is one of the most effective factors in windbreak structures (Hashemi Monfared et al., 2019).

Through the results of research, it was found that wind speed have an important role in reducing evaporation rate for summer season and showed in Figures 1,2 and 3. Based on the empiricist relationship, a direct connection has been detected between wind speed and the evaporation, as the evaporation rate increases when wind speed increase, therefore, one unit change of wind velocity creates the clear change in evaporation compared to other factors such as dew point. The experiment proved the significant role of wind speed in evaporation rate limitation. By calculating the actual evaporation of the evaporation basin class A for all scenarios by using Equation (1). Figures 1, 2, and 3 illustrated the gradual decline in the evaporation rate within the summer season.

The following factors have clear effect on the windbreaks; windbreaks height and its number of rows and way of installed it where affect on air density and this is the reason beyond declining 
scenario 1

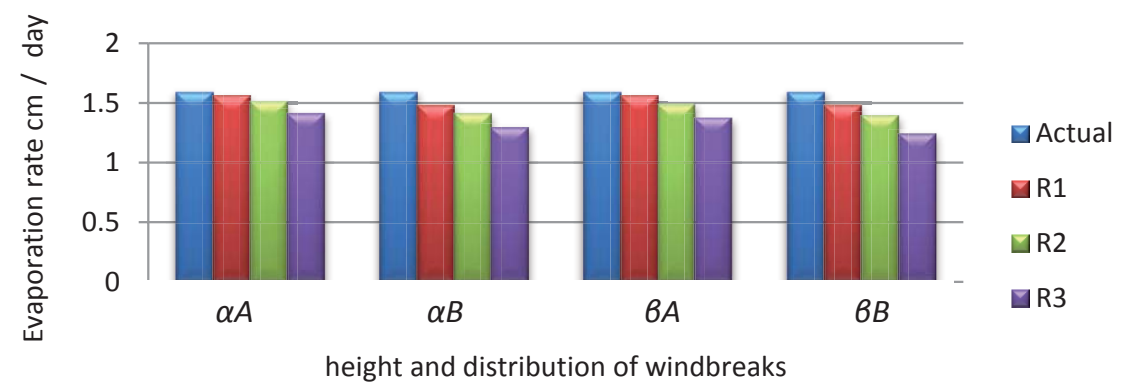

scenario 2

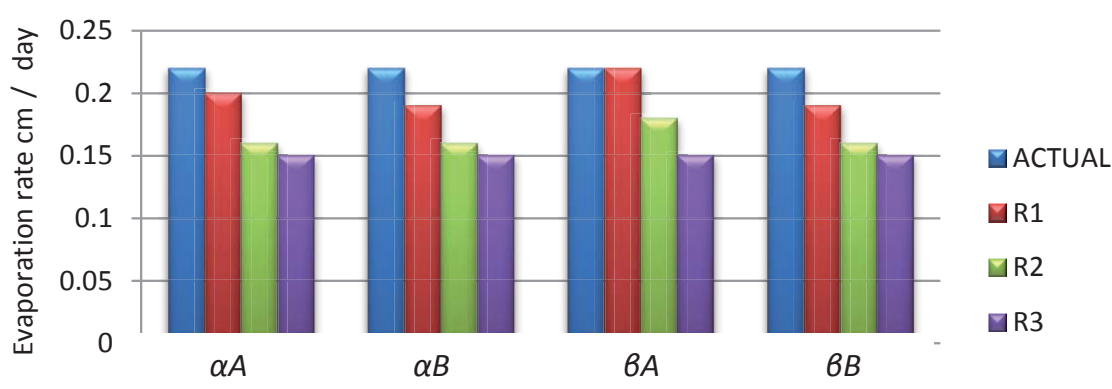

height and distribution of windbreaks

scenario 3

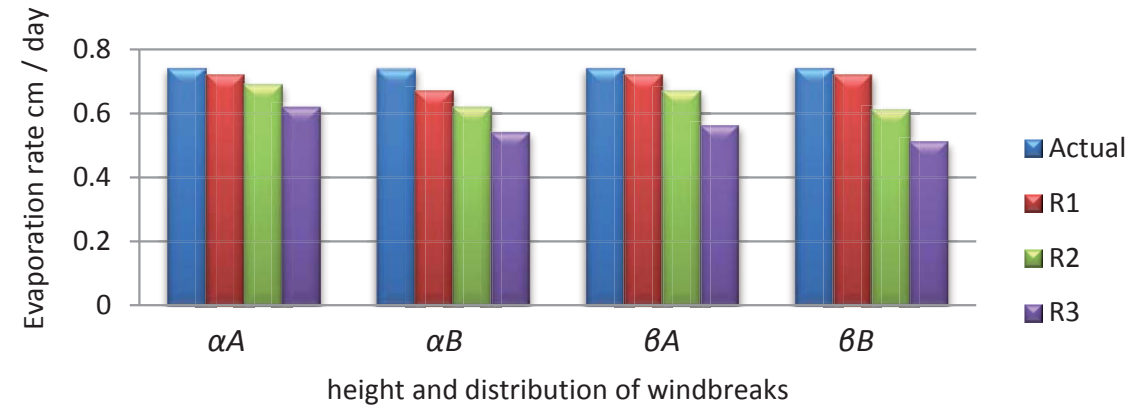

Actual - measuring wind speed without using windbreaks; $\alpha$ - distributing windbreak in parallel case, $\beta$ - distributing windbreak in intersection case, $A$ - trees' height of $50 \mathrm{~cm}, B$ - trees' height of $100 \mathrm{~cm}$; $\mathrm{R} 1$ - one row of trees, $\mathrm{R} 2$ - two rows of trees, $\mathrm{R} 3$ - three rows of trees.

FIGURE 1. Histogram for the effect windbreaks on evaporation rate for three scenarios in June 


\section{scenario 1}

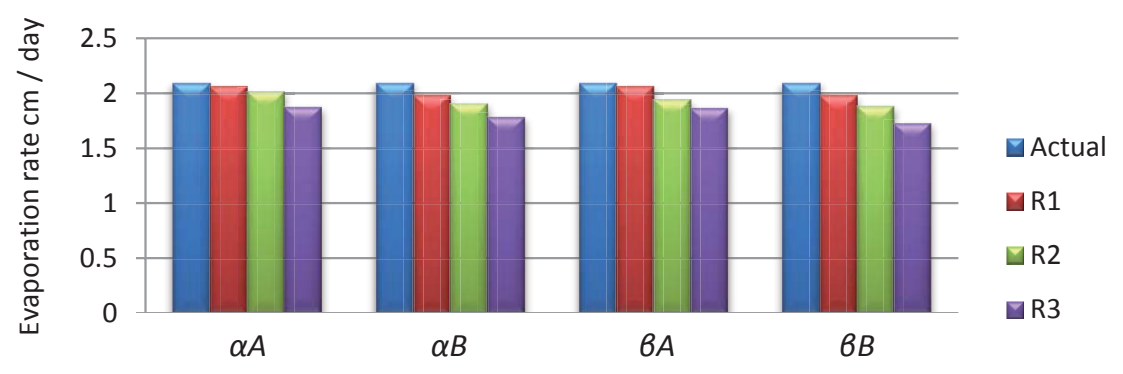

height and distribution of windbreaks

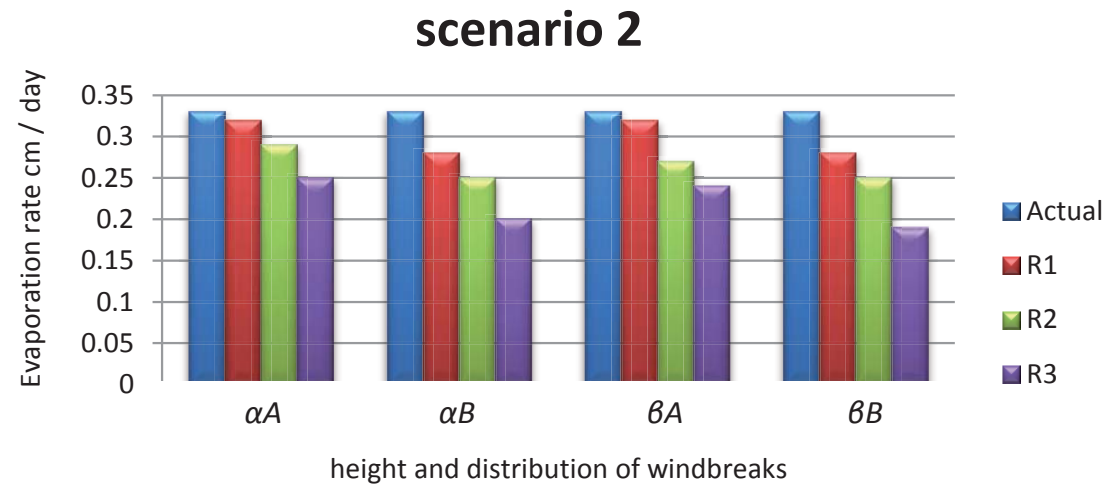

scenario 3

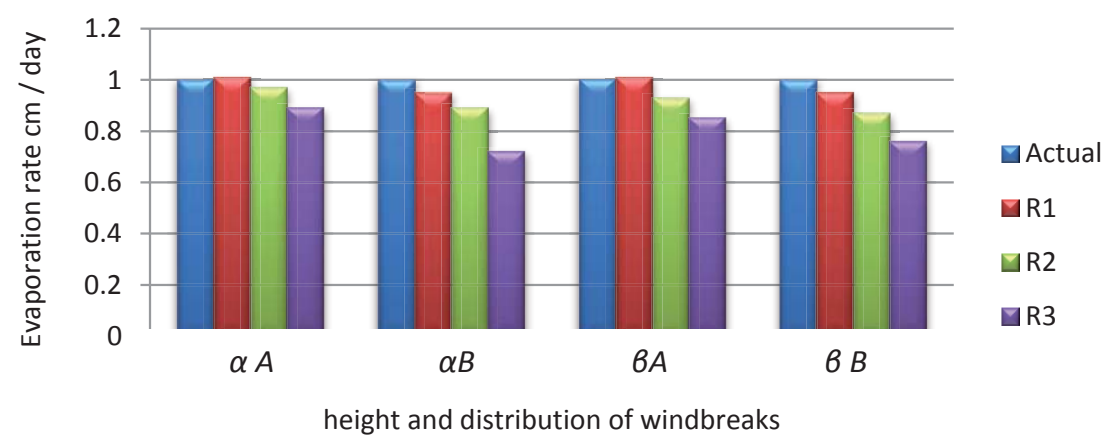

Actual - measuring wind speed without using windbreaks; $\alpha$ - distributing windbreak in parallel case, $\beta$ - distributing windbreak in intersection case, $A$ - trees' height of $50 \mathrm{~cm}, B$ - trees' height of $100 \mathrm{~cm}$; $\mathrm{R} 1$ - one row of trees, $\mathrm{R} 2$ - two rows of trees, R3 - three rows of trees.

FIGURE 2. Histogram for the effect windbreaks on evaporation rate for three scenarios in July 


\section{scenario 1}

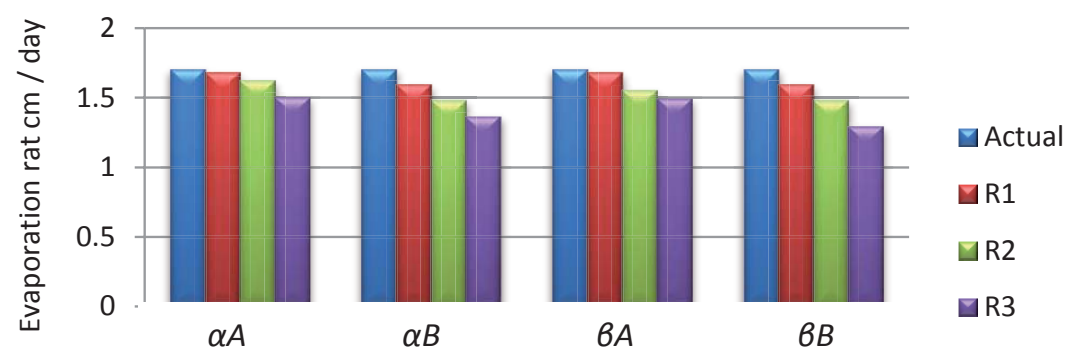

height and distribution of windbreaks

scenario 2

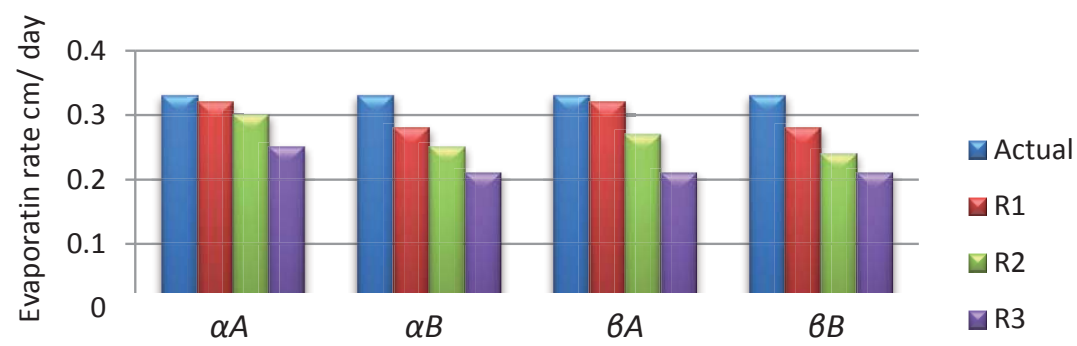

height and distribution of windbreaks

\section{scenario 3}

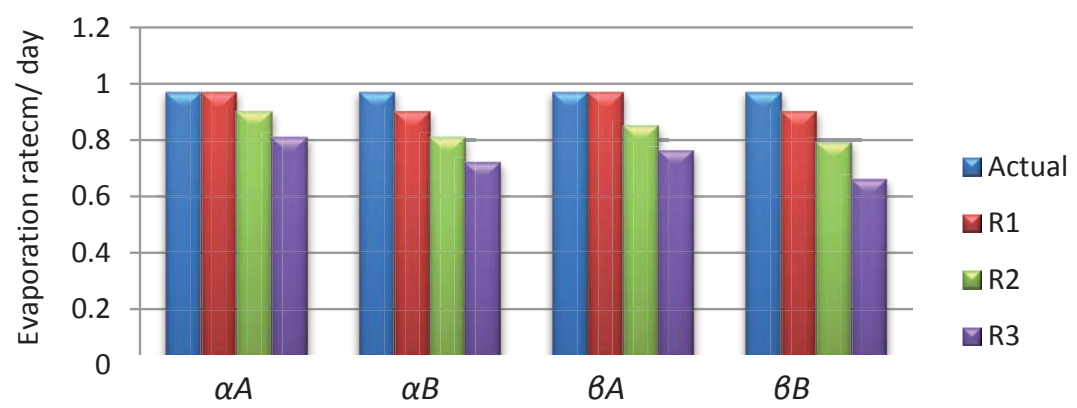

height and distribution of windbreaks

Actual - measuring wind speed without using windbreaks; $\alpha$ - distributing windbreak in parallel case, $\beta$ - distributing windbreak in intersection case, $A$ - trees' height of $50 \mathrm{~cm}, B$ - trees' height of $100 \mathrm{~cm}$; $\mathrm{R} 1$ - one row of trees, R2 - two rows of trees, R3 - three rows of trees.

FIGURE 3. Histogram for the effect windbreaks on evaporation rate for three scenarios in August 
the evaporation rate in the three scenarios as shown in Figures 1, 2 and 3.

The effect of wind on evaporation is evident in different ratio and for all months. As the sub-scenario R3 in the S1 and $\mathrm{S} 3$ of the scenario is in all months given the best result of reducing evaporation up 35\% to almost but in a scenario S2 there was no clear change because the wind was originally the min value.

The best experiment results were when the height of the fenders was $100 \mathrm{~cm}$, the number of fenders 3, and the method of installing the windbreaks in crosses case [ $\beta \mathrm{BR} 3]$ recorded the highest rate of evaporation reduction up to $35 \%$ of its original value before using windbreaks.

\section{Conclusions}

Through this study it was found that windbreaks have a very important role in reducing wind speed. This depends on the height, density of the trees and number of rows. The best experiment results are when the height of the windbreak was $100 \mathrm{~cm}$, the number of row 3 , and the method of installing windbreaks in crosses case [ $\beta B R 3]$ recorded the highest rate of evaporation reduction up to $35 \%$ of its original value before using windbreaks. Eventually, it can be concluded that the wind is one of the most important factors that have effect on the evaporation rate, it is considered one of the best methods because it is environmentally friendly, unlike chemical methods that affect the environment and living organisms in lakes so the windbreaks can adopted to control the evaporation rate.
In addition to this use, the windbreaks can be used to protect from sand dunes and to protect strategic crops from the impact of wind speeds.

\section{Recommendations}

1. Study on the best types of trees that can be used as windbreaks.

2. Study effect trees on wildlife. lakes.

3. Applying this study in small

\section{Acknowledgements}

The authors would like to thank Prof. Dr Monim Hakeem Khalaf Al-Jiboori followed in the Atmospheric Sciences Department, the College of Science, the Mustansiriyah University, for his comments and suggestions in improving the paper and also editing English writing.

\section{References}

Al-Echrish, A.A. (2001). Modeling of evaporation in Iraq (master's thesis). Baghdad: Al-Mustansiriyah University.

Álvarez, V.M., Baille, A., Martínez, J.M.M. \& Real, M.M.G. (2006). Effect of black polyethylene shade covers on the evaporation rate of agricultural reservoirs. Spanish Journal of Agricultural Research, 4, 280-288.

Benzaghta, M.A. \& Mohamad, T.A. (2009). Evaporation from reservoir and reduction methods: an overview and assessment study. International Engineering Convention. Domascus, Syria and Medinah, Kingdom of Saudi Arabia, 11-18 May 2009. Domascus, Syria and Medinah, Kingdom of Saudi Arabia: IEC.

Brandle, J.R. \& Finch, S. (1991). EC91-1763-B How windbreaks work. Lincoln: University of Nebraska-Lincoln. 
Brandle, J.R., Hintz, D.L. \& Sturrock, J. (2012). Windbreak technology. Amsterdam: Elsevier Science.

Campi, P., Palumbo, A. \& Mastrorilli, M. (2009). Effects of tree windbreak on microclimate and wheat productivity in a Mediterranean environment. European Journal of Agrono$m y, 30(3), 220-227$.

Cooley, K.R. (1970). Energy relationships in the design of floating covers for evaporation reduction. Water resources research, 6(3), 717-727.

Cooley, K.R. \& Myers, L.E. (1973). Evaporation reduction with reflective covers. Journal of the Irrigation and Drainage Division, 99(3), 353-363.

Erick, S. (2007). Controlling evaporation losses from large storage dams using chemical monolayers. Report. Toowoomba: University of Southern Queensland, Australia.

Hashemi Monfared, S.A., Rezapour, M. \& Zhian, T. (2019a). Using windbreaks for decreasing lake and reservoir evaporation: a case study from Iran. Polish Journal of Environmental Studies, 28(4), 1-10.

Hashemi Monfared, S.A., Zoraghi, K., Azhdary Moghaddam, M., Dehghani Darmian, M. \& Abdollahi, A. (2019b). Comparison and measurement of evaporation from water surface of the reservoirs in arid areas and evaluation of a glass cover to reduce evaporation. Journal of Hydrosciences and Environment, 3(5), 14-29.

Hong, S.W., Lee, I.B. \& Seo, I.H. (2015). Modelling and predicting wind velocity patterns for windbreak fence design. Journal of Wind Engineering and Industrial Aerodynamics, 142, 53-64.

Kim, R.W., Lee, I.B., Kwon, K.S., Yeo, U.H., Lee, S.Y. \& Lee, M.H. (2018). Design of a windbreak fence to reduce fugitive dust in open areas. Computers and Electronics in Agriculture, 149, 150-165.

Manual, A.F. (1990). Illinois Extension Forestry. Illinois: Riverside Publishing.

Singh, V. \& Xu, C.Y. (1997). Evaluation and generalization of 13 mass-transfer equations for determining free water evaporation. Hydrological Processes, 11(3), 311-323.
Vacek, Z, Řeháček, D, Cukor, J., Vacek, S., Khel, T., Sharma, R.P., Kučera J., Král, J. \& Papaj, V. (2018). Windbreak efficiency in agricultural landscape of the Central Europe: multiple approaches to wind erosion control. Environmental Management, 62(5), 942-954.

Yao, X., Zhang, H., Lemckert, C., Brook, A. \& Schouten, P. (2010). Evaporation reduction by suspended and floating covers: overview, modelling and efficiency. Urban Water Security Research Alliance Technical Report, 28, $1-13$.

Yusaiyin, M. \& Tanaka, N. (2009). Effects of windbreak width in wind direction on wind velocity reduction. Journal of Forestry Research, 20(3), 199-204.

\section{Summary}

Scenarios to reduce evaporation from class A evaporation pan by using windbreaks. Evaporation from reservoirs and lakes is an important processes frequently occurring in dry, hot regions such as Iraq. In order to preserve the environment and to reduce the amount of evaporation from open water bodies in this study, simulation was performed to reduce evaporation from evaporation basin class A by using windbreaks natural (Conocarpus trees). Three basic scenarios were made that depended on the values of the atmospheric elements affecting the evaporation process in summer according to the modified Penman equation for the conditions of Iraq, the climate factors are temperature, solar radiation, wind speed, dew point, and the effect of the number of windbreaks and their height was also introduced in sub- scenario. Experiments have shown that the best sub-scenario for all basic scenarios is when the windbreaks are placed in a direct direction to the wind blowing on the evaporation basin in the form of three rows, each row contains three trees where the windbreaks are in case cross and the height of the trees is $100 \mathrm{~cm}$ and the distance between 
each tree and another, and between each row and row $15 \times 15 \mathrm{~cm}$, the results of this subscenario recorded the highest rate of evaporation reduction up to $35 \%$ of its original value before using windbreaks.

\section{Authors' address:}

Mustafa O. Oribi - corresponding author (https://orcid.org/0000-0003-4414-9328)

Iraqi Ministry of Agriculture

Agricultural Meteorological Network

Mustansiriyah University

College of Science

Department of Atmospheric Sciences

Bagdad, Iraq

e-mail: mustafaudah425@gmail.com

Asraa K. Abdulkareem

(https://orcid.org/0000-0003-2103-0295)

Mustansiriyah University

College of Science

Department of Atmospheric Sciences

Bagdad, Iraq

e-mail: dr.asraa.atmsc@uomustansiriyah.edu.iq 